\title{
Implementasi Program Kotaku dalam Upaya Mengatasi Pemukiman Kumuh di Kabupaten Lima Puluh Kota
}

\author{
Vira Handika, Rahmadani Yusran \\ Jurusan Ilmu Administrasi Negara \\ FIS Universitas Negeri Padang \\ E-mail: virahandikaa@gmail.com
}

\section{ABSTRAK}

Penelitian ini bertujuan untuk menganalisis implementasi Program Kotaku (Kotaku Tanpa Kumuh) dalam upaya mengatasi pemukiman kumuh di Kenagarian Piobang, Kecamatan Payakumbuh Kabupaten Lima Puluh Kota. Program Kotaku merupakan usaha dari direktoral jendral cipta karya dalam mendukung RPJMN Tahun 2015-2019 dalam rangka menguramgi pemukiman kumuh menjadi pemukiman yang layak huni, produktif dan berkelanjutan serta meningkatkan akses terhadap infrastuktur masayarakat. Metode penelititian ini adalah kualitatif dengan menggunakan pendekatan deskriptif. Informan penelitian ditentukan dengan cara purposive sampling. Teknik pengumpulan data dilakukan dengan cara melakukan wawancara, observasi dan studi dokumentasi serta dilakukan reduksi data agar bisa ditarik kesimpulan yang akurat dari data yang telah didapat. Hasil penelitian menunjukan implementasi Program Kotaku dalam mengurangi pemukiman kumuh di Kabupaten Lima Puluh Kota kenagarian Piobang dalam aspek tertentu sudah terlaksana dalam bentuk Pembuatan Drainase Lingkungan dan jalan. Dalam tahap ini adanya dukungan dari implementor seperti Mengadakan pelatihan-pelatihan, melakukan pengawasan. Dalam implementasi ini dekerjakan sesuai dengan SOP yang ada atau dalam Pogram kotaku disebut dengan Pedoman Umum Kotaku. Namun demikian Implementasi Program Kotaku dalam aspek lainnya Seperti Sosialisasi sudah terlaksana namun belum mampu meningkatkan pemahaman masyarakat terhadap maksud dan tujuan program kotaku. Kemudian dalam aspek SDA Seperti sumber daya manusia sudah mencukupi namun dalam partisipasi masyarakat kurang terhadap kegiatan program, dan masih terbatasnya sumber daya fasilitas dalam kegiatan seperti pembebasan lahan, dan sumber daya anggran yang masih kurang mencukupi.

Kata Kunci: implementasi kebijakan, program kotaku, pemukiman kumuh

\section{ABSTRACT}

This aim of this study isto Analyse the implementation of Kotaku Tanpa Kumuh (Kotaku) without slums in dealing with slum settments in Nagari Piobang, Payakumbuh Subdisrict, fifty cities. This Program by the Directoral Jendral Cipta Karya to support the fulfilment of the RPJMN for 2015-2019in order to reduce slums to liveable, productive and sustaiable settlements and increase acces to comunity infrastucture. This research method is 
qualitative descriptive approach. The informans are determined by purposive sampling . Data was colected by interviewing. Observation, documentation study and do date reduction so that an accurate conclusion can be drawn from the date that has been obained. The results showed that the implementation of the Kotaku Program in reducing slum settlements in Lima Puluh regency of the City of Piobang in certain aspects had already been carried out in the form of the Making of Environmental and Road Drainage. At this stage there is support from the implementor such as Conducting trainings, conducting supervision. In this implementation, it is carried out in accordance with the existing SOPs or in my city program called the General Guidelines for My City. However, the implementation of the Kotaku program in other aspects such as the socialization has been carried out but has not been able to increase the community's understanding of the aims and objectives of the My Town program. Then in the aspects of natural resources such as human resources are sufficient but in the community participation is less in program activities, and still limited facility resources in activities such as land acquisition, and budget resources are still insufficient.

Keywords: policy implementation, my city program, slums

(c) (7) (2) This work is licensed under the Creative Commons Attribution-ShareAlike 4.0 International License. EY

\section{PENDAHULUAN}

Permasalahan pemukiman kumuh menjadi salah satu isu utama dan menimbulkan polemik perkotaan. Di satu sisi dinamika penangannya berhadapan dengan tumbuh kembangnya pemukiman dan kawasan kumuh baru. Pada sisi lain pemukiman kumuh terus menimbulkan citra negatif dan terkesan pemerintah tidak mampu mengatasi pemukiman kumuh. Fenomena ini, bertentangan dengan UU Nomor 1 tahun 2011 yang mengatur pemerintah dari tingkat pusat hingga daerah bertanggung jawab melindungi segenap bangsa Indonesia melalui pelaksanaan perumahan dan kawasan permukiman agar masyarakat mampu bertempat tinggal serta menghuni rumah yang layak. Pemukiman kumuh adalah suatu pemukiman yang tidak layak huni karena ketidakteraturan bangunan, tingkat kepadatan bangunan yang tinggi dan kualitas bangunan dan sarana dan prasarana yang tidak memenuhi syarat (Irvan, 2018).

Dalam Peraturan Presiden No 2 Tahun 2015 tentang Rencana Pembangungan Jangka Menengah Nasional (RPJMN) mengamanatkan pembangunan dan pengembangan kawasan perkotaan melalui penanganan kualitas lingkungan pemukiman yaitu peningkatan kualitas pemukiman kumuh. Oleh karena itu dalam rangka mewujudkan RPJMN direktorat jendral cipta karya menginisiasi pembangunan kolaborasi melalui Program Kotaku (Kotaku Tanpa Kumuh).

Program Kotaku mulai di realisasikan tanggal 27 april 2016, dimana program kotaku ini adalah 
lanjutan dari Program Nasional Pemberdayaan Masyarakat Mandiri Perkotaan (PNPM-MP). Program kotaku adalah Program pencegahan dan peningkatan kualitas permukiman kumuh nasional yang merupakan upaya strategis direktorat jenderal cipta karya kementerian pekerjaan umum dan perumahan rakyat dalam rangka memberdayakan masyarakat dan memperkuat peran pemerintah daerah kabupaten atau kota dalam rangka pencegahan dan peningkatan kualitas kawasan permukiman kumuh diperkotaan demi mendukung pencapaiaan gerakan 100-0-100 (100\% tersedia akses air minum, 0\% kawasan kumuh dan $100 \%$ tersedia akses

sanitasi layak) sesuai dengan amanah RPJMN. Tujuan umum dari Program Kotaku adalah meningkatkan akses terhadap infrastuktur dan pelayanan dasar pada kawasan kumuh dan untuk mendukung terwujudnya pemukiman yang layak huni produktif dan berkelanjutan. (Yolanda,2018).

Sesuai dengan Surat keterangan Bupati kabupaten Lima Puluh Kota Nomor 535 Tahun 2017 Tentang Surat Keputusan (SK) kumuh di kabupaten limapluh kota, Program ini di laksanakan di kecamatan payakumbuh dimana 7 dari lokasi sasaran program kotaku telah di laksanakan di nagari piobang pada tahun 2017 dengan luas wilayah kumuh sebesar 33,31 Ha (Republika, 12 November 2019). Berdasarkan temuan penelitian, di Nagari Piobang implementasi program kotaku bertujuan mendukung mewujudkan perkotaan yang layak huni, berkelanjutan, produktif, dipimpin pemerintahan yang berkaloborasi dengan pemangku kepentingan baik dalam implementasi maupun perencanaan dan mengikut sertakan masyarakat.

Namun demikian, implementasi program kotaku di Nagari Piobang dalam aspek tertentu telah terlaksanakan tetapi, pada aspek lainnya belum optimal. Misalnya, akses terhadap infrastuktur dan pelayanan dasar pada kawasan kumuh belum terbangun sebagaimana mestinya. Hal ini, karena masih terbatasnya sarana dan prasarana pengolahan persampahan. Belum tersedia-nya tempat sampah dengan pemilihan sampah pada skala domestik rumah tangga, serta bak pembungan sampah. Kemudian, drainase lingkungan masih berupa galian tanah. Akibatnya, drainase tersebut tidak mampu mengalirkan limpahan air hujan sehingga menimbulkan genangan.

Masalah lainnya dalam implementasi program Kotaku adalah masih banyak terdapat pemukiman kumuh di Nagari Piobang. Hal ini terjadi karena terbatas jumlah anggaran yang disediakan untuk mengurangi kawasa kumuh. Selain itu, pembangunan kawasan belum memperoleh dukungan dari masyarakat sebab partisipasi masyarakat dalam melaksanakan program Kotaku yang disebabkan karena sosialisasi yang dilakukan terbatas sehingga masih ada masyarakat yang tidak paham maksud dan tujuan program.

Berdasarkan uraiandiatas maka penulis merasa perlu untuk lebih mendalami Program Kota Tanpa Kumuh dalam upaya mengatasi pemukiman kumuh dan faktor pendorong dan penghambat dalam implementasi program tersebut. 


\section{METODE PENELITIAN}

Metode deskriptif merupakan suatu metode yang digunakan untuk membuat gambaran secara sistematis mengenai hubungan antara fenomena yang diselidiki dan hasilnya tidak dinyatakan dalam bentuk angka. Menurut Bogdan dan Taylor (dalam Sugiyono, 2012:22), penelitian kualitatif adalah prosedur penelitian yang menghasilkan data deskriptif berupa kata-kata tertulis atau lisan dari orang-orang dan perilaku yang dapat diamati. Penelitian kualitatif dengan metode deskriptif adalah suatu jenis penelitian yang bertujuan untuk membuat deskripsi, atau gambaran secara sistematis, faktual dan akurat mengenai fakta-fakta, sifat-sifat serta hubungan antara fenomena yang diselidiki. Penelitian dilakukan di nagari Piobang Kecamatan Payakumbuh Kabupaten Lima Puluh Kota.

Informan dalam penelitian ini yang akan memberikan data dan informasi dalam menjawab permasalahan yang peneliti lakukan ini ditentukan dengan teknik purposive sampling yaitu menentukan informan dengan pertimbangan tertentu yanng dipandang dapat memahami secara mendalam tentang informasi yang akan peneliti dapatkan dan juga memberikan waktu dan data yang diperlukan dalam penelitian memberikan data secara maksimal (Moleong, 2005:132). Informan penelitian meliputi Tim Koordinator Kotaku, Fasilisator Kotaku, Badan Kswadayaan Masyarakat, Wali Nagari dan Masyarakat.

Data yang digunakan berupa data primer yang bersumber dari wawancara dan observasi secara langsung dengan informan serta meliputi data sekunder yang didapatkan berupa dari hasil studi dokumentasi dan. Tingkat validitas terhadap penelitian ini berupa kegiatan yang bertujuan untuk mengetahui bahwa apa yang diamati telah sesuai dengan keadaan yang sebenarnya untuk mendapatkan data yang kredibilitas tinggi maka penelitian ini digunakan dalam bentuk pemeriksaan keabsahan data dengan menggunakan teknik triangulasi. Peneliti menggunakan teknik triangulasi sumber sebab teknik memeriksa keabsahan data yang memanfaatkan sesuatu yang lain diluar data sehingga data tersebut dapat dipercaya.

\section{HASIL DAN PEMBAHASAN}

\section{Implementasi Kebijakan Program Kotaku dalam Upaya Mengatasi Pemukiman Kumuh}

Implementasi

kebijakan merupakan rangkaian aktivitas yang dilakukan dalam rangka mewujudkan tujuan-tujuan kebijakan yang sudah ditetapkankan sebelumnya. Melalui aktivitas implementasi diketahui upaya yang dilakukan pihak-pihak terkait mengoptimalkan capaian tujuan kebijakan (Aprina, Y \& Yusran, R., 2020). Dengan pemahaman seperti itu, maka implementasi Program Kotaku sebenarnya berkaitan erat dengan upaya yang dilakukan pihakpihak terkait dalam mengoptimalkan capaian tujuan Program Kotaku.

Program kotaku di Nagari Piobang sudah di laksanakan pada tahun 2017 sesuai dengan Surat Keputusan Bupati Kabupaten Lima Puluh Kota Nomor 535 tahun 2017. Dimana program ini sudah dapat mewujudkan kebijakan meningkatkan 
Journal of Civic Education (ISSN: 2622-237X)

Volume 3 No. 32020

akses terhadap infrastuktur, mengurangi kumuh. Hal ini dapat dilaksanakan karena adanya dukungan yang di berikan oleh Direktoral Pekerja umum, Bupati, Koordinator Program Kotaku, Tim Fasilisator, Camat, Wali nagari, Badan Kswadayan Masyarakat serta masyarakat Nagari Piobang. Dalam pelaksanaan program di Nagari Piobang dilakukan dengan tahap perencanaan seperti sosialisasi, selanjutnya tahap pelaksanaan dimana dari tahun 2017 sampai tahun 2018 sudah dilakukanya pembuatan drainase lingkungan dan jalan.

Temuan penelitian ini mengungkapkan implementasi Program Kotaku dilakukan melalui beberapa bentuk kegiatan seperti dari aspek perencanaan dilakukan sosialisasi, mengadakan pelatihanpelatihan, serta pelaksanaan pembuatan drainase lingkungan dan jalan. Pertama, dari aspek perencanaan, dalam hal ini dilakukan kegiatan sosialiasi. Sosialisasi program sudah dilaksanakan dalam bentuk penyampaian tujuan dan manfaat program kepada masyarakat. Namun demikian, sosialisasi program lingkup pelaksanaannya hanya terbatas pada kelompok masyarakat tertentu yang menjadi sasaran program. penelitian ini menemukan sebagian besar masyarakat yang menjadi sasaran kebijakan tidak mengetahui tujuan dan manfaat Program Kotaku.

\section{Kotaku dilaksanakan melalui} pelatihan-pelatihan yang diberikan ke KSM (Kelompok Keswadayaan Masyarakat). Dalam pelatihan KSM Diberikan materi seperti mekanisme bantuan pemerintah, manajemen kontruksi, tahapan pencairan, teknik perencanaan, teknik pelaksanaan dan pelaporan serta pembukuan KSM. Pelatihan terhadap KSM biasanya dilaksanakan di kantor wali nagari Piobang, pelatihan KSM merupakan persyaratan sebelum dana dari BDI PLBK dimanfaatkan oleh KSM.

Ketiga, dalam aspek pembuatan drainase lingkungan dan jalan juga sudah terlaksana di beberapa KSM seperti, Somak Kelok Tabiang Ciek, Somak Kelok Tabiang Ciek Duo, Somak Rawang, Caniago 1 dan Berkah. Pelaksanaan pembuatan drainese lingkugan dan jalan ini secara lengkap dapat dilihat pada tabel di bawah ini:

Tabel Daftar Pelaksanaan kegiatan Kotaku di Nagari Piobang Tahun 2017-2018

\begin{tabular}{|c|c|c|c|c|c|c|c|}
\hline $\begin{array}{l}N \\
0\end{array}$ & $\begin{array}{l}\text { Nama } \\
\text { KSM }\end{array}$ & $\begin{array}{c}\text { Jenis } \\
\text { Sarana } \\
\text { dan } \\
\text { prasarana }\end{array}$ & Dana BDI & $\begin{array}{c}\text { Satua } \\
\mathrm{n}\end{array}$ & $\begin{array}{c}\text { Volu } \\
\text { me }\end{array}$ & $\begin{array}{c}\text { Lokasi } \\
\text { (RT/RW) } \\
\text { Kondisi }\end{array}$ & Tahun \\
\hline 1 & $\begin{array}{l}\text { Somak } \\
\text { Kelok } \\
\text { Tabiang } \\
\text { Ciek }\end{array}$ & $\begin{array}{l}\text { Jalan \& } \\
\text { drainase }\end{array}$ & 172.500 .000 & Meter & 355 & $\begin{array}{c}\text { JR001- } \\
00000 \\
\text { Baik }\end{array}$ & 2017 \\
\hline 2 & $\begin{array}{l}\text { Somak } \\
\text { Kelok } \\
\text { Tabiang } \\
\text { duo }\end{array}$ & $\begin{array}{l}\text { Jalan \& } \\
\text { drainase }\end{array}$ & 172.500 .000 & Meter & 353 & $\begin{array}{c}\text { JR001- } \\
00000 \\
\text { Baik }\end{array}$ & 2017 \\
\hline 3 & $\begin{array}{l}\text { Somak } \\
\text { Rawang }\end{array}$ & $\begin{array}{l}\text { Jalan \& } \\
\text { drainase }\end{array}$ & 150.000 .000 & Meter & 520 & $\begin{array}{c}\text { JR001- } \\
00000 \\
\text { Baik }\end{array}$ & 2017 \\
\hline 4 & $\begin{array}{l}\text { Somak } \\
\text { Kelok } \\
\text { Tabiang } \\
\text { Ciek }\end{array}$ & $\begin{array}{l}\text { Jalan \& } \\
\text { drainase }\end{array}$ & 177.000 .000 & Meter & 336 & $\begin{array}{c}\text { JR001- } \\
00000 \\
\text { Baik }\end{array}$ & 2018 \\
\hline 5 & $\begin{array}{l}\text { Caniago } \\
1\end{array}$ & $\begin{array}{l}\text { Jalan \& } \\
\text { drainase }\end{array}$ & 168.000 .000 & Meter & 260 & $\begin{array}{c}\text { JR001- } \\
00000 \\
\text { Baik }\end{array}$ & 2018 \\
\hline 6 & Berkah & $\begin{array}{l}\text { Jalan \& } \\
\text { drainase }\end{array}$ & 150.000 .000 & Meter & 255 & $\begin{array}{c}\text { JR001- } \\
00000 \\
\text { Baik }\end{array}$ & 2018 \\
\hline
\end{tabular}

Sumber: Data Nagari Piobang

Namun

demikian, pembangunan drainase lingkungan dan jalan dalam Program Kotaku belum sesuai dengan tujuan. Kualitas aksesibilitas masyarakat dari program ini belum lancar, karena masih banyak ditemukan dibagian jalan yang 
berlobang dan berpotensi menimbulkan banjir ketika hujan. Selain itu, pembuatan jalan lingkup yang bertujuan untuk meningkatkan akses masyarakat di Nagari Piobang tidak terawat dengan baik dan masih adanya jalan yang belum siap karena dana yang belum mencukupi. Kondisi seperti ini, juga turut dipengaruhi oleh perilaku masyarakat yang membuang sampah tidak pada tempatnya. Permasalahan inilah yang menyebabkan belum optimalnya implementasi program Kotaku di Nagari Piobang.

\section{Faktor yang Mempengaruhi Implementasi Program Kotaku di Nagari Piobang}

Dalam sebuah implementasi program tentu ada faktor yang mempengaruhi keberhasilan atau kegagalan dalam sebuah pelaksanaan. Edward III dalam Indiohono (2009) mengatakan bahwa ada empat faktor yang dapat mempengaruhi keberhasilan atau kegalalan implementasi kebijakan yakni komunikasi, sumber daya, disposisi, dan stuktur birokrasi. Edward menjelaskan bahwa keempat variabel yang mempengaruhi implementasi saling berinteraksi satu sama lain.

\section{a. Komunikasi}

Keberhasilan

dalam implementasi kebijakan mensyaratkan agar implementor mengetahui apa yang harus dilakukan. Apa yang menjadi sasaran dan tujuan (target group) sehingga akan dapat mengurangi distorsi implementasi. Komunikasi yang di kemukakan oleh Edward III dapat mempengaruhi implementasi. Pertama proses komunikasi yang dilakukan jelas tersampaikan. Dalam implementasi
Program kotaku di nagari piobang komunikasi dilakukan melalui sosialisasi.

Namun demikian, ada kalanya faktor sosialisasi mengalami kendalakendala. Menurut Edward III dalam (Indiohono, 2009: 31) implementasi program dapat gagal karena isi dan tujuan tidak tersampaikan sehingga masyarakat tidak mengetahui isi program. Akibatnya tidak ada dukungan dari masyarakat terhadap pelaksanaan program. Dalam hal tertentu sosialisasi sudah dilakukan namun terbatas pada daerah tertentu dan tidak dilakukan pada daerahdaerah yang banyak masyarakatnya yang menjadi kelompok sasaran dari program. Semestinya sebagaimana yang di ungkap oleh Edward dalam Indihiono (2009:31) Komunikasi itu harus dilaksanakan dengan secara komprensif terutama terhadap kelompok-kelompok masyarakat yang menjadi sasaran dari program dan tidak hanya terbatas dilakukan pada kelompok masyarakat tertentu saja. Inilah faktor yang mempengaruhi keberhasilan Implementasi Program Kotaku di Nagari Piobang.

b. Rendahnya Dukungan Sumber Daya Implementasi Program

Sumber daya pendukung implementasi program kotaku di Nagari Piobang seperti sumber daya manusia, fasilitas dan anggaran. Menurut Edward III dalam (indhiono 2009: 31) Sumber daya adalah faktor yang penting dalam proses implementasi program atau tujuan program. Akan tetapi dalam implementasi program Kotaku masih terbatasnya sumber daya.

Pertama, sumber daya manusia sudah memadai, dimana sumber daya 
Journal of Civic Education (ISSN: 2622-237X)

Volume 3 No. 32020

manusia dalam program sudah mendukung implementasi karena implementor dalam program ini cukup memadai dan kompeten serta berkerja sesuai dengan bidang masingmasing. Meskipun demikian implementasi program belum di dukung sepenuhnya oleh masyarakat, dimana kurangnya partisipasi sebagian masyarakat dalam program kotaku. Misalnya dalam perencanaan program, dalam kegiatan sosialisasi semakin hari semakin berkurang masyrakat yang datang, dan yang datang hanya orang itu-itu saja. Begitupun dalam kegiatan pelaksanaan, masih adanya masyarakat yang tidak mau ikut serta dalam kegiatan seperti gotong royong hal ini juga di sebabkan karena kesibukan pekerjaan dari masyarakat tersebut, hal lainnya karena masyarakat yang jauh tinggal dari lokasi pembangunan tidak mau datang ikut serta dalam kegiatan tersebut.

Kedua, fasilitas yang belum memadai. Sumber daya fasilitas merupakan sarana yang digunakan untuk operasionalisasi program. Namun dalam pelaksanaan kurangnya fasilitas seperti lahan untuk pelaksanaan pembangunan, dimana masih adanya masyarakat yang tidak mau membebaskan lahan mereka untuk pembangunan dikarenakan tidak adanya imbalan. Dalam pelaksanan program ini pembebasan lahan menjadi salah satu faktor yang menghambat implementasi program karena lahan atau tanah bukan milih pemerintah melainkan tanah pribadi. Selanjutnya peralatan dalam kegiatan pelaksanan program kotaku masih terbatasnya jumlah cangkul, sekop, molen, sapu sehingga dalam kegiatan menggunakan alat pribadi dari masyarakat. Peralatan dalam pengurangan pemukiman kumuh masih terbatas, seperti bak sampah dimana di Nagari Piobang belum adanya disediakan bak sampah, hanya saja awal tahun 2020 baru disediakan becak sampah.

Ketiga, Sumber daya anggaran, anggaran dalam implementasi program kotaku hanya dari APBN, tidak adanya bantuan dari pihak nagari yang terkait dalam pelaksanaan program.

\section{c. Disposisi}

Menunjuk sikap yang harus ada dalam diri seorang implementor atau pelaksanan sebuah kebijakan atau program. Dimana seorang implementor mempunyai kejujujuran, komitmen serta demokratis. Implementor yang mempunyai komitmen yang tinggi dan jujur akan senantiasa bertahan di antara hambatan yang di hadapi dalam sebuah proses implementasi. Jika dilihat dari implentasi Program Kotaku ini karakteristik implementor merupakan salah satu bentuk pengaruh terhadap implementasi program tersebut. Ini dapat dilihat dari komitmen pelaksana dalam dalam melakukan pengawasan terhadap program.

Implementasi Program Kotaku di Nagari Piobang sudah sesuai dengan tujuan program. Komitmen implementor terlihat dari bentuk dukungan yang diberikan secara langsung dalam setiap kegiatan. Misalnya, dukungan berupa pelatihanpelatihan sebelum kegiatan di mulai. Kemudian, dukungan dalam bentuk pengawasan langsung di lapangan, melakukan evaluasi atau monev, 
sesuai dengan alur yang ada di dalam SOP.

Dukungan yang diberikan oleh implementor secara signifikan telah mendorong pelaksanaan program ke arah tujuan yang sudah ditetapkan sebelumnya. Temuan ini sesuai dengan yang di ungkapkan Van Meter dan Van Horn dalam (Agustino, 2008:195), Wahab, 2014:133) implementasi kebijakan adalah tindakan-tindakan yang dilakukan baik oleh individu-individu/pejabatpejabat atau kelompok-kelompok pemerintah atau swasta yang diarahkan tercapainya tujuan-tujuan yang digariskan dalam keputusan kebijakan. Dimana sering dianggap sebagai bentuk pengorganisasian dan penyelenggaraan aktivitas yang telah ditetapkan sesuai dengan undangundang dan menjadi kesepakatan bersama diantara beragam pemangku kepentingan (stakeholder) atau sektor organisasi. Temuan ini didukung oleh pendapat Gordon dalam (Deddy Mulyadi, 2016:24) dimana implementasi merupakan langkah yang sangat penting dalam proses kebijakan yang berkenaan dengan berbagai kegiatan yang di arahkan pada realisasi program.

Namun demikian, keberhasilan implementasi program tidak hanya di fokuskan pada masalah komitmen dari implementor saja sebagaimana yang dikemukakan Edward III; Van Meter dan Van Horn dalam (Agustino, 2008:195), Wahab, 2014:133) dan Gordon dalam (Deddy Mulyadi, 2016:24) akan tetapi perlu didukung oleh masyarakat sebagai kelompok sasaran kebijakan. Penelitian ini berpendapat, dukungan kelompok masyarakat akan mempermudah capaian tujuan kebijakan. Bahkan, apabila terdapat komitmen yang kuat antara implementor dengan kelompok masyarakat mempermudah capaian tujuan kebijakan.

\section{d. Stuktur Birokrasi}

George Edward III Dalam (Mulyadi, 2015:68) mengatakan bahwa stuktur birokrasi merupakan variabel keempat dalam implementasi kebijakan. Struktur birokrasi menjadi hal yang penting dalam sebuah kebijakan yang mencakup mekanisme dan stuktur organisasi pelaksana. Struktur organisasi yang bertugas dalam implementasi kebijakan mempunyai pengaruh signifikan terhadap pelaksanaan kebijakan. Salah satu aspek yang penting dalam stuktur organisasi adalah SOP yang dapat dijadikan pedoman bagi implementor dalam sebuah pelaksanaan kebijakan. Dalam pelaksanaan Program Kotaku yang bertanggung jawab di tingkat nasional adalah Dinas Pekerja Umum Dan Perumahan Rakyat.

Di tingkat Provinsi adanya Gubernur, dan di tingkat kabupaten atau kota seperti Bupati atau wali kota. Di Nagari Piobang mendapat intruksi langsung dari Bupati setelah di keluarkan SK kumuh yang di serahkan kepada Tim Koorkot Kabupaten Lima Puluh Kota, dimana terdiri dari Koordinator, Askot serta Fasilisator Kotaku. Di tingkat Nagari Piobang Seperti Perangkat Nagari adanya dibentuk Badan Keswadayaan Masyarakat serta Kelompok Swadaya Masyarakat. Pelaksanaan sudah sesuai dengan Standar Operation Prosedur (SOP) dan Pedoman Umum Kotaku. 


\section{KESIMPULAN}

Berdasarkan hasil penelitian yang dilakukan penulis mengenai implementasi Program Kotaku maka disimpulkan bahwa Implementasi Program Kotaku dalam mengurangi pemukiman kumuh di Kabupaten Lima Puluh Kota Kenagarian Piobang dalam aspek tertentu sudah terlaksana dalam bentuk pembuatan drainase lingkungan dan jalan. Dalam tahap ini adanya dukungan dari implementor seperti mengadakan pelatihanpelatihan, melakukan pengawasan. Dalam implementasi ini dikerjakan sesuai dengan SOP yang ada atau dalam Pogram disebut dengan Pedoman Umum Kotaku.

Namun demikian Implementasi Program Kotaku dalam aspek lainnya seperti sosialisasi sudah terlaksana namun belum mampu meningkatkan pemahaman masyarakat terhdap maksud dan tujuan program. Kemudian dalam aspek sumber daya manusia sudah mencukupi namun dalam partisipasi masyarakat kurang mendukung kegiatan program, dan masih terbatasnya sumber daya fasilitas dalam kegiatan seperti pembebasan lahan, dan sumber daya anggaran yang masih kurang mencukupi.

\section{DAFTAR PUSTAKA}

Agustino, Leo.2008. Dasar-dasar Kebijakan Publik. Bandung. CV Alvabeta

Aprina, Y., \& Yusran, R. (2020). Implementasi Peraturan Daerah Kota Bukittinggi Nomor 2 Tahun $2015 \quad$ Tentang Pencegahan dan Penanggulangan Bahaya Kebakaran. Jurnal Mahasiswa Ilmu
Administrasi Publik, 1(4), 87-97. Retrieved from http://jmiap.ppj.unp.ac.id/index.php /jmiap/article/view/49

Indiahono, Dwiyanton. 2009.

Kebijakan Publik Berbasis Dynamic Policy Analysis. Yogyakarta: Grava Media

Irvan, Eka Putri Hafidzita. 2018. Partisipasi Masyarakat dalam Program Kota Tanpa Kumuh (KOTAKU) di Kelurahan Pesisir Kecamatan Limapuluh Kota Pekanbaru. JOM FISIP Vol 5 No 1

Keputusan Bupati Kabupaten 50 Kota Nomor 535 Tahun 2017 tentang Penetapan lokasi KawasanPerumahan dan Pemukiman kumuh di Kabupaten Lima Puluh kota.

Moleong, J. Lexy. 2013.Metode Penelitian Kualitatif. Bandung: PT Rosdakarya

Mulyadi, Deddy. 2016. Studi Kebijakan Public Dan Pelayanan Publik. Bandung: Penerbit Alfabeta

Pedoman Umum Program KOTAKU diakses tanggal 25 desember 2019

Sugiyono, 2017. Metode Penelitian Kuantitatif, Kualitatif, Kombinas. Bandung: Alvabeta.s

UU No 1 Tahun 2011 Tentang Perumahan dan Kawasan Kumuh

UU No 2 tahun 2015 tentang Rencana Pembangunan Jangka Menengah Nasional 2015-2019

Wahab, Abdul Solichin. 2014. Analisis Kebijakan: Dari formulasi ke penyusunan model-model Implementasi Kebijakan Publik. Jakarta. Bumi Aksara 
286 | implementasi program..

Yolanda, Sylvia. 2018. Strategi

Komnikasi Konsultan

Manajemen Wilayah dalam

Program KOTAKU di

kelurahan Tanah Datar

Kec.Pekanbaru. Jomb Fisip

Volume 5 No

https://www.republika.co.id di akses tanggal 12 November 2019 